Sains Malaysiana 46(7)(2017): 1061-1067

http://dx.doi.org/10.17576/jsm-2017-4607-07

\title{
Pencirian Pertumbuhan Lapisan Nano Grafin di atas Elektrod antara Digit Superkapasitor MEMS
}

(Characterization of Graphene Nanolayers Grown on MEMS Interdigital Supercapacitor Electrode)

\author{
HAFZALIZA ERNY ZAINAL ABIDIN, AZRUL AZLAN HAMZAH* \& BURHANUDDIN YEOP MAJLIS
}

\begin{abstract}
ABSTRAK
Superkapasitor MEMS khususnya dengan reka bentuk elektrod antara digit (IDE), telah menarik minat pada masa kini dalam bidang seperti bioMEMS, bioperubatan implan, peranti kuasa elektronik dan aplikasi berkuasa tinggi disebabkan kapasiti pengecasannya yang tinggi. Kajian ini membentangkan superkapasitor MEMS dengan lapisan nano grafin tumbuh di atas elektrod. Superkapasitor MEMS terdiri daripada silikon dioksida ( $\left.\mathrm{SiO}_{2}\right)$, nikel, grafin, polipirol (Ppy) dan lapisan alkohol polivinil (PVA). Tumpuan diberikan kepada fabrikasi struktur lapisan nano grafin atas elektrod superkapasitor MEMS melalui beberapa proses seperti pemendapan wap kimia secara peningkatan plasma (PECVD), penyejatan alur e dan salutan pusing. Grafin tumbuh melalui proses PECVD selama 10 minit pada kuasa 40 Watt dan pada suhu antara $400^{\circ} \mathrm{C}$ dan $1000^{\circ} \mathrm{C}$. Spektrum Raman menunjukkan puncak pada 1340 dan $1580 \mathrm{~cm}^{-1}$ mewakili jalur D dan G .Puncak $2 \mathrm{D}$ wujud dalam julat 2600 - $3000 \mathrm{~cm}^{-1}$. Nisbah bagi keamatan puncak $2 \mathrm{D}$ terhadap puncak $\mathrm{G}$ pada $1000^{\circ} \mathrm{C}$ adalah 0.43 menunjukkan kualiti yang baik bagi banyak lapisan grafin.
\end{abstract}

Kata kunci: Bioperubatan implan; elektrod antara digit; grafin tumbuh; pemendapan wap kimia secara peningkatan plasma (PECVD); superkapasitor MEMS

\section{ABSTRACT}

MEMS supercapacitor, specifically with interdigital (IDE) electrodes design, has recently gained much interest in fields such as biomEMS, biomedical implants, power electronic devices and high power applications due to its high charging capacity. This research presents a MEMS supercapacitor with graphene nanolayers grown on its electrodes. The MEMS supercapacitor consists of silicon dioxide $\left(\mathrm{SiO}_{2}\right)$, nickel, graphene, polypyrrole (Ppy) and polyvinyl alcohol (PVA) layers. This paper more focus on the fabrication of graphene nanolayer structures on MEMS supercapacitor electrodes via several subsequent plasma-enhanced chemical vapor deposition (PECVD), E-beam evaporation and spin coating processes. PECVD graphene was grown for 10 min at 40 Watt at temperatures between $400^{\circ} \mathrm{C}$ and $1000^{\circ} \mathrm{C}$. Raman spectrum indicates peaks at 1340 and $1580 \mathrm{~cm}^{-1}$ corresponding to $D$ and $G$ band, respectively. The $2 D$ peaks appear in range of 2600 to 3000 $\mathrm{cm}^{-1}$. The intensity ratio of $2 \mathrm{D}$ and $\mathrm{G}$ peaks at $1000^{\circ} \mathrm{C}$ is 0.43 , which indicates a good quality of multilayer graphene.

Keywords: Biomedical implants; graphene grown; interdigital electrode (IDE); MEMS supercapacitor; plasma-enhanced chemical vapor deposition (PECVD)

\section{PENGENALAN}

Superkapasitor MEMS khususnya dengan reka bentuk elektrod antara digit (IDE), telah menarik minat pada masa kini dalam bidang seperti bioMEMS, bioperubatan implan, peranti kuasa elektronik dan aplikasi berkuasa tinggi disebabkan kapasiti pengecasannya yang tinggi (Marsi et al. 2015; Zainal Abidin et al. 2013). MEMS berasaskan sensor, penggerak dan peranti elektronik mula bertapak dalam industri elektronik pada hari ini kerana kebolehpercayaan, keteguhan dan kemampuan untuk mencipta peranti dengan fungsi yang lebih luas (Hamzah et al. 2004; Marsi et al. 2012). Superkapasitor MEMS boleh difabrikasi melalui beberapa proses MEMS seperti proses pemendapan dan punaran (Hamzah et al. 2013, 2007). Terkini, ramai penyelidik memberi tumpuan kepada peningkatan prestasi utama superkapasitor MEMS iaitu kemuatan, keselamatan peranti dan kelajuan pengecasan
(Chen et al. 2015). Grafin merupakan salah satu bahan yang boleh digunakan untuk meningkatkan prestasi superkapasitor MEMS kerana sifat unggulnya seperti kekonduksian elektrik yang tinggi, kestabilan elektrokimia yang baik dan sifat mekanik yang sangat baik (Aziz et al. 2008; Terasawa \& Saiki 2012; Zheng et al. 2012). Selain itu, grafin terdiri daripada alotrop karbon dalam bentuk dua dimensi yang mempunyai permukaan yang luas $\left(2630 \mathrm{~m}^{2} / \mathrm{g}\right)$, Modulus Young (1.0 TPa), kekonduksian terma $\left(\sim 5000 \mathrm{Wm}^{-1} \mathrm{~K}^{-1}\right)$ dan kehantaran optik $(\sim 97.7 \%)$ (Ho et al. 2014; Novoselov et al. 2012; Zhu et al. 2010). Terdapat beberapa teknik untuk pertumbuhan grafin dengan masing-masing mempunyai kelebihan dan kekurangan yang tersendiri. Antara teknik yang digunakan seperti endapan wap kimia (CVD), pemendapan wap kimia secara peningkatan plasma (PECVD) dan haba endapan wap kimia (T-CVD) (Zheng et al. 2013). Antara kelebihan teknik 
PECVD adalah proses endapan boleh dicapai pada suhu dan tekanan yang rendah disebabkan kehadiran spesies reaktif yang dihasilkan oleh plasma (Terasawa \& Saiki 2012).

Dalam kajian ini, kami membincangkan proses fabrikasi dan pencirian grafin yang tumbuh di atas elektrod antara digit superkapasitor MEMS daripada segi suhu yang berbeza. Dalam kajian ini, grafin tumbuh pada suhu antara $400^{\circ} \mathrm{C}$ sehingga $1000^{\circ} \mathrm{C}$ untuk melihat kesan suhu terhadap kualiti penghasilan grafin yang baik dan berkualiti tinggi. Grafin dianalisis menggunakan spektroskopi Raman dan spektroskopi sinar X fotoelektron (XPS). Manakala pancaran medan mikroskopi elektron pengimbasan (FESEM) dan mikroskopi daya atom (AFM) digunakan untuk menganalisis morfologi pertumbuhan lapisan nano grafin di atas elektrod antara digit.

\section{BAHAN DAN KAEDAH}

\section{METOD DAN PROSES BAHAN}

Substrat $\mathrm{SiO}_{2}$ digunakan sebagai bahan asas untuk fabrikasi superkapasitor MEMS. Pertumbuhan langsung grafin pada elektrod antara digit adalah melalui proses PECVD, penyejatan alur elektron dan salutan pusing. Proses fabrikasi superkapasitor MEMS dimulakan dengan proses endapan Ni setebal $100 \mathrm{~nm}$ dengan corak elektrod antara digit melalui proses penyejatan alur elektron. Kemudian, grafin tumbuh di atas lapisan Ni menggunakan PECVD. Selepas itu, lapisan Ni dan grafin disalut dengan Polipirol (Ppy) untuk mewujudkan lapisan dielektrik. Alkohol polivinil (PVA) diisi di antara jari elektrod yang berfungsi sebagai elektrolit keadaan pepejal. PVA merupakan polimer konjugat yang dipilih sebagai bahan aktif kerana kos yang rendah dan ketumpatan pengecasan yang tinggi. Rajah 1 menunjukkan proses fabrikasi lengkap superkapasitor MEMS antara digit. Walau bagaimanapun, pada masa ini, kami berada pada peringkat pertumbuhan grafin di atas elektrod antara digit.
Pertumbuhan langsung grafin di atas elektrod antara digit melalui proses PECVD dilakukan selama 10 min pada suhu antara $400^{\circ} \mathrm{C}$ sehingga $1000^{\circ} \mathrm{C}$ pada kuasa tetap iaitu sebanyak 40 Watt (Rajah 2). Antara pelbagai teknik yang digunakan dalam pertumbuhan grafin, PECVD dianggap sebagai salah satu proses yang terbaik kerana kelebihannya seperti suhu operasi yang rendah, risiko yang lebih rendah terhadap keretakan pada lapisan endapan dan mudah dikawal untuk paten struktur nano. Dalam sistem PECVD, metana $\left(\mathrm{CH}_{4}\right)$ digunakan secara meluas sebagai sumber karbon. Parameter proses PECVD seperti prekursor, kuasa plasma dan masa memainkan peranan yang penting untuk memastikan grafin yang berkualiti dapat dihasilkan.

\section{KEPUTUSAN DAN PERBINCANGAN}

\section{ANALISIS PERTUMBUHAN GRAFIN MENGGUNAKAN SPEKTROSKOPI RAMAN}

Spektroskopi Raman merupakan alat yang penting untuk mengenal pasti kewujudan grafin dan ia dapat ditentukan melalui kehadiran jalur D, jalur G dan jalur 2D (Wang et al. 2008). Spektroskopi Raman juga boleh digunakan untuk menentukan bilangan lapisan grafin melalui nisbah keamatan puncak jalur 2D terhadap jalur G. Rajah 3(a) menunjukkan spektrum Raman pada suhu pertumbuhan $400^{\circ} \mathrm{C}$. Daripada spektrum tersebut, didapati jalur D, jalur $\mathrm{G}$ dan jalur 2D tidak wujud. Ini mengesahkan bahawa tiada grafin wujud pada suhu $400^{\circ} \mathrm{C}$. Rajah 3(b) menunjukkan spektrum Raman pada suhu pertumbuhan $600^{\circ} \mathrm{C}$. Tiga jalur telah wujud iaitu jalur $\mathrm{D}$, jalur $\mathrm{G}$ dan jalur 2D dengan keamatan puncak pada julat $1340 \mathrm{~cm}^{-1}$ dan $1580 \mathrm{~cm}^{-1}$ masing-masing mewakili jalur D dan G. Keamatan puncak jalur 2D wujud dalam julat 2600 $3000 \mathrm{~cm}^{-1}$. Dalam rajah ini, puncak 2D amat luas, dengan nisbah $\mathrm{I}_{2 \mathrm{D}} / \mathrm{I}_{\mathrm{G}}$ adalah 0.33 . Apabila suhu pertumbuhan grafin meningkat seperti yang ditunjukkan dalam Rajah
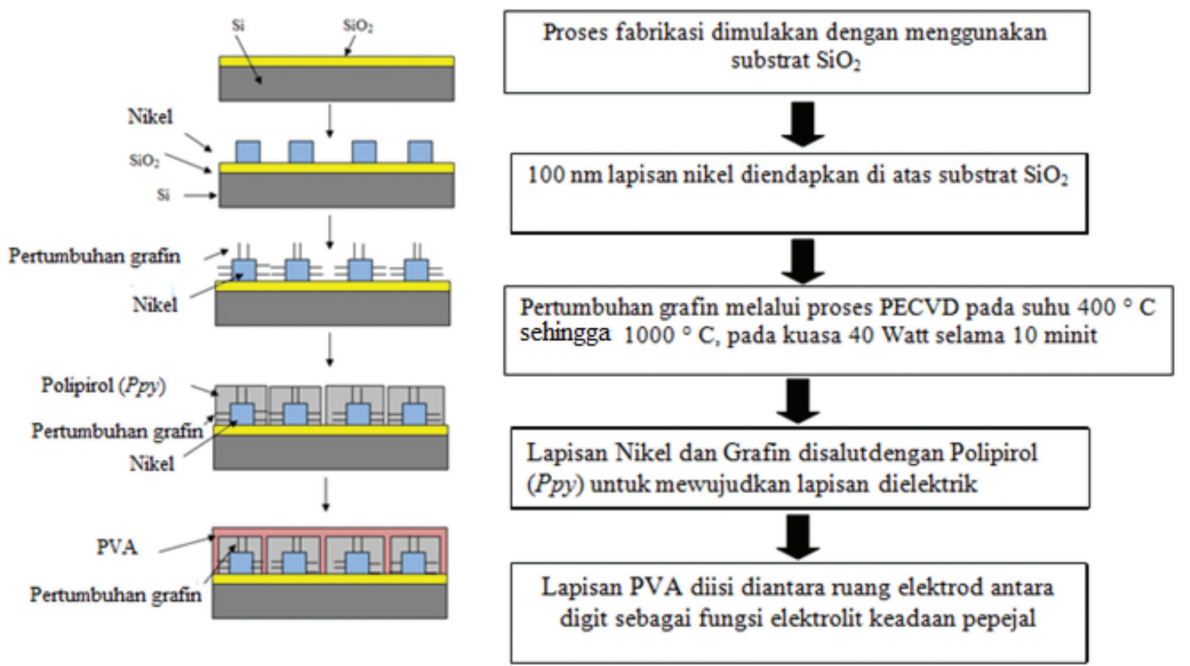

RAJAH 1. Proses fabrikasi lengkap superkapasitor MEMS antara digit melalui pemendapan wap kimia secara peningkatan plasma (PECVD) 
3(c), jalur D, yang mewakili kecacatan pada grafin, mula berkurangan berbanding jalur D dalam Rajah 3(b). Di sini, menunjukkan nisbah $\mathrm{I}_{2 \mathrm{D}} / \mathrm{I}_{\mathrm{G}}$ adalah 0.18 . Nisbah $\mathrm{I}_{2 \mathrm{D}} / \mathrm{I}_{\mathrm{G}}$ dikira untuk menentukan bilangan lapisan grafin.

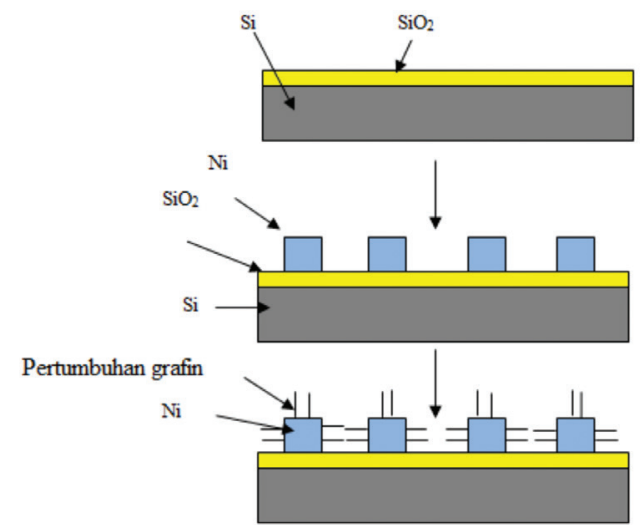

RAJAH 2. Pertumbuhan grafin pada elektrod antara digit superkapasitor MEMS

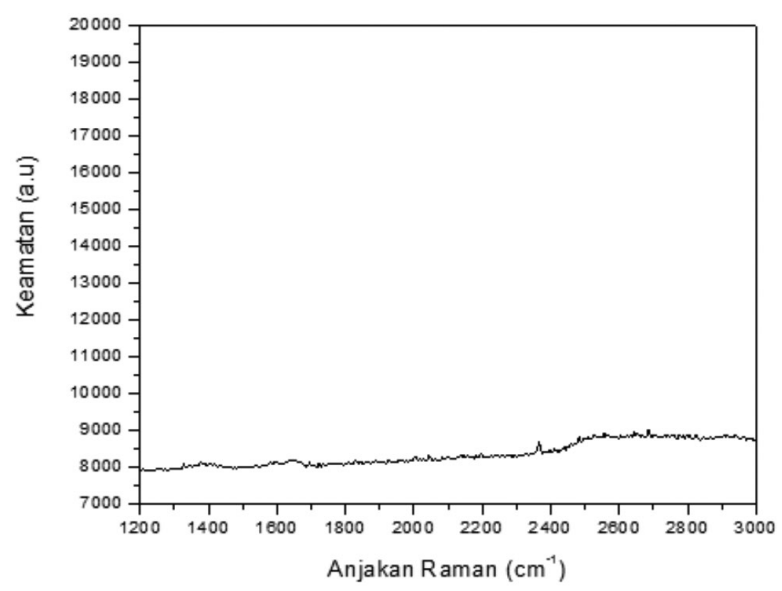

(a)

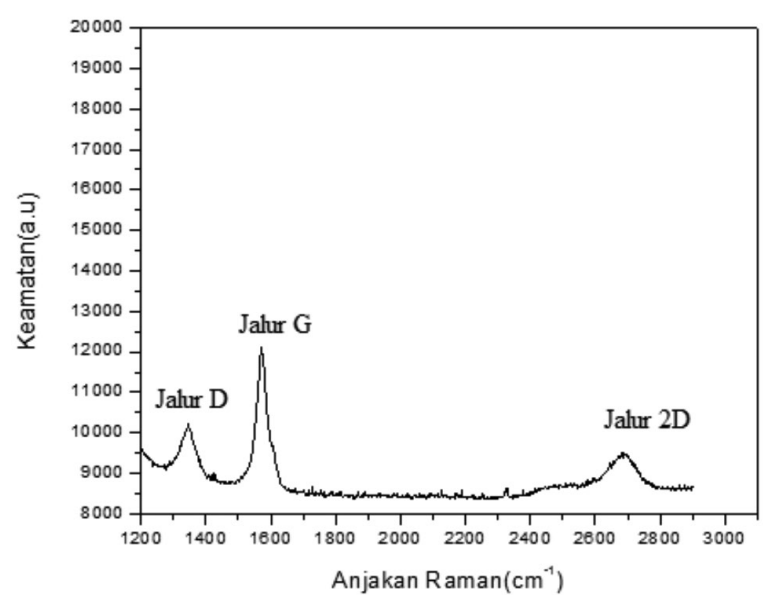

(c)
Daripada nilai nisbah tersebut menunjukkan banyak lapisan grafin telah dihasilkan. Merujuk kepada Rajah 3(d), kecacatan yang rendah (nilai keamatan puncak jalur D yang rendah), didapati bahawa kualiti grafin yang baik telah dihasilkan pada elektrod antara digit superkapasitor MEMS. Daripada nilai nisbah tersebut, dapat disimpulkan bahawa kecacatan pada grafin berkurangan apabila suhu pertumbuhan grafin bertambah. Nilai nisbah $\mathrm{I}_{2 \mathrm{D}} / \mathrm{I}_{\mathrm{G}}$ berkurangan dengan peningkatan bilangan lapisan grafin. Ini bermaksud semakin kecil nilai nisbah $\mathrm{I}_{2 \mathrm{D}} / \mathrm{I}_{\mathrm{G}}$, semakin banyak lapisan grafin akan terhasil. Berdasarkan Rajah 3(d), kita boleh melihat bahawa jalur 2D lebih tajam pada suhu $1000^{\circ} \mathrm{C}$ berbanding suhu lain. Nisbah $\mathrm{I}_{2 \mathrm{D}} / \mathrm{I}_{\mathrm{G}}$ pada suhu $1000^{\circ} \mathrm{C}$ adalah 0.43 . Kelebaran penuh pada separa maksimum (FWHM) jalur 2D digunakan untuk menentukan kualiti dan bilangan lapisan grafin. Berdasarkan Rajah $3 \mathrm{~d}$, FWHM adalah $60 \mathrm{~cm}^{-1}$ yang menunjukkan bahawa 5 lapisan grafin terbentuk (Lin et al. 2015). Jadual 1(a) menunjukkan hubungan antara nilai nisbah $\mathrm{I}_{2 \mathrm{D}} / \mathrm{I}_{\mathrm{G}}$, bilangan lapisan grafin dan FWHM manakala Jadual 1(b) menunjukkan hubungan antara suhu, nilai nisbah $\mathrm{I}_{2 \mathrm{D}} / \mathrm{I}_{\mathrm{G}}$ dengan bilangan lapisan grafin.

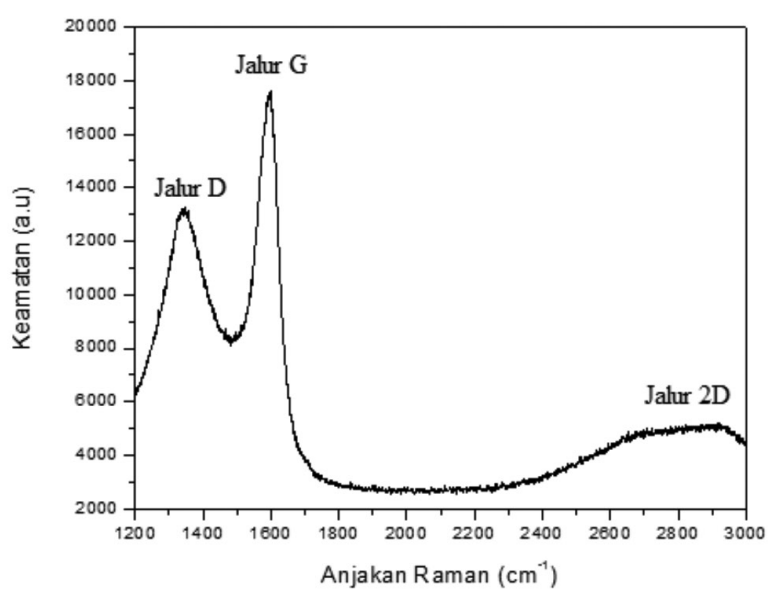

(b)

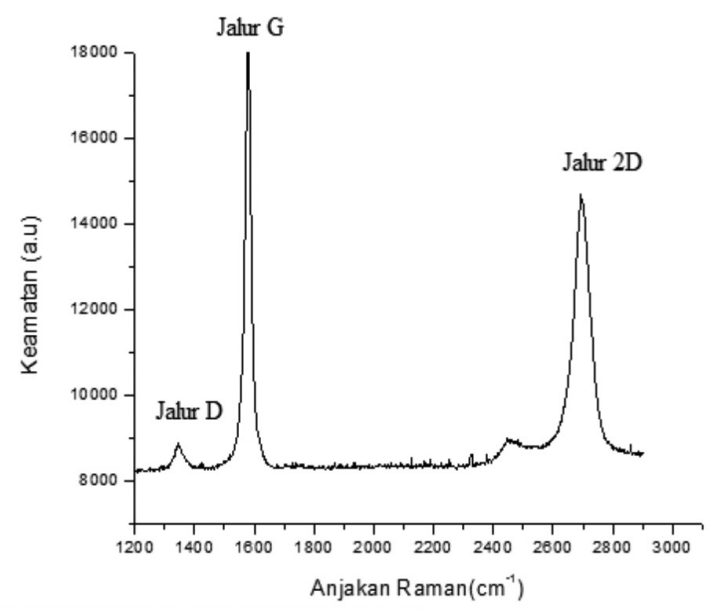

(d)

RAJAH 3. Spektrum Raman pada suhu pertumbuhan grafin yang berbeza (a) $400^{\circ} \mathrm{C}$ (b) $600^{\circ} \mathrm{C}$ (c) $800^{\circ} \mathrm{C}$ (d) $1000^{\circ} \mathrm{C}$ 


\section{ANALISIS EDX BAGI PEMBENTUKAN GRAFIN PADA ELEKTROD ANTARA DIGIT}

EDX telah digunakan untuk mengenal pasti unsur-unsur yang terdapat pada sampel pertumbuhan. Analisis EDX atas sampel pertumbuhan menunjukkan komposisi 48.7\% karbon, $47.7 \%$ silikon dan $3.6 \%$ nikel seperti yang ditunjukkan dalam Rajah 4. Peratusan karbon yang tinggi menunjukkan kehadiran grafin pada elektrod antara digit superkapasitor MEMS. Morfologi permukaan pertumbuhan grafin itu dicirikan menggunakan FESEM. Rajah 5(a) menunjukkan struktur pertumbuhan grafin atas permukaan elektrod antara digit. Rajah 5(b) mendedahkan banyak kedutan yang terhasil pada permukaan elektrod superkapasitor MEMS. Struktur kedut dikenal pasti wujud daripada lapisan nikel, yang cenderung untuk mengecut selepas proses endapan pada suhu yang tinggi. Rajah 5(c)-5(e) menunjukkan bahawa struktur grafin kolumnar tumbuh seragam dan meliputi keseluruhan kawasan elektrod superkapasitor ini.

\section{ANALISIS KEKASARAN PERMUKAAN GRAFIN YANG TERBENTUK PADA SUHU YANG BERBEZA}

AFM adalah salah satu kaedah untuk pencirian kekasaran permukaan yang tidak memerlukan sebarang penyediaan sampel. Daripada imej AFM, kita boleh menentukan kekasaran permukaan melalui nilai punca min kuasa dua (RMS). Morfologi permukaan pertumbuhan grafin pada lapisan nikel elektrod antara digit ditunjukkan dalam Rajah 6(a)-6(d). Berdasarkan rajah tersebut, kita mendapati bahawa nilai kekasaran permukaan bertambah secara langsung dengan kenaikan suhu. Jadual 2 menunjukkan nilai kekasaran permukaan nilai punca min kuasa dua (RMS) pada pelbagai suhu antara $400^{\circ} \mathrm{C}$ hingga $1000^{\circ} \mathrm{C}$. Daripada segi sifat kekonduksian elektrik, lapisan grafin yang lebih tebal mempunyai kekonduksian yang lebih rendah. Oleh sebab itu, kita perlu memastikan bahawa lapisan grafin yang dihasilkan tidak terlalu tebal di samping dapat menghasilkan kualiti grafin yang baik.
Kekasaran permukaan biasanya dikaitkan dengan saiz butiran. Berdasarkan kajian Moon et al. (2010), kecacatan pada lapisan grafin berkadar songsang dengan saiz butiran. Dalam erti kata lain, apabila kecacatan rendah, saiz butiran adalah tinggi. Ini membawa kepada kerintangan yang rendah membawa kepada kekonduksian elektrik yang tinggi.

\section{KOMPOSISI IKATAN SP² BAGI PERTUMBUHAN GRAFIN}

Bersama-sama dengan analisis yang dinyatakan seperti di atas, kita perlu mengesahkan bahawa lapisan yang tumbuh mempunyai ikatan atom grafin. Oleh kerana grafin mempunyai kekonduksian elektrik yang luar biasa, adalah penting untuk mengesahkan bahawa lapisan yang tumbuh mempunyai ikatan C-C sp ${ }^{2}$. Spektroskopi sinar X fotoelektron (XPS) adalah teknik yang digunakan untuk menentukan komposisi unsur melalui penyinaran bahan dengan pancaran sinar X. Rajah 7 menunjukkan analisis

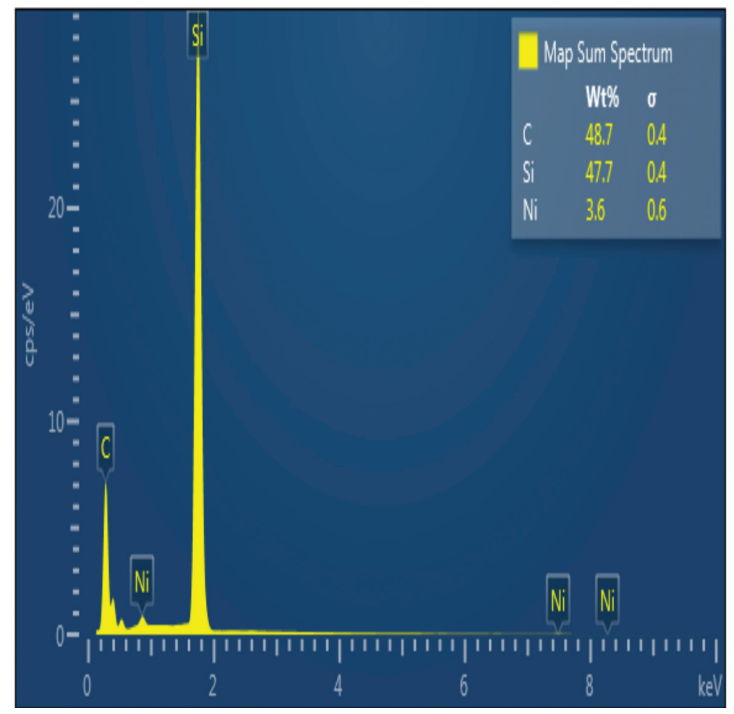

RAJAH. 4 Analisis EDX bagi struktur pertumbuhan grafin

JADUAL 1. (a) Hubungan antara nilai nisbah $\mathrm{I}_{2 \mathrm{D}} / \mathrm{I}_{\mathrm{G}}$, bilangan lapisan grafin dan FWHM

\begin{tabular}{lll}
\hline Nisbah $\mathrm{I}_{2 \mathrm{D}} / \mathrm{I}_{\mathrm{G}}$ & Bilangan lapisan grafin & $\begin{array}{l}\text { Kelebaran penuh pada separa maksimum } \\
(\mathrm{FWHM}) \text { jalur 2D }\end{array}$ \\
\hline$>2$ & Satu lapisan & $26.3 \mathrm{~cm}^{-1}$ \\
1 & Dua lapisan & $52.1 \mathrm{~cm}^{-1}$ \\
$<0.5$ & Banyak lapisan grafin & $56.1 \mathrm{~cm}^{-1}$ (3 lapisan) \\
& & $60.0 \mathrm{~cm}^{-1}$ (5 lapisan) \\
\hline
\end{tabular}

JADUAL 1. (b) Hubungan suhu, nilai nisbah $\mathrm{I}_{2 \mathrm{D}} / \mathrm{I}_{\mathrm{G}}$ dengan bilangan lapisan grafin

\begin{tabular}{ccc}
\hline Suhu $\left({ }^{\circ} \mathrm{C}\right)$ & Nisbah $\mathrm{I}_{2 \mathrm{D}} / \mathrm{I}_{\mathrm{G}}$ & Bilangan lapisan grafin \\
\hline 400 & - & Tiada grafin \\
600 & 0.33 & Banyak lapisan grafin \\
800 & 0.18 & Banyak lapisan grafin \\
1000 & 0.43 & 5 lapisan \\
\hline
\end{tabular}



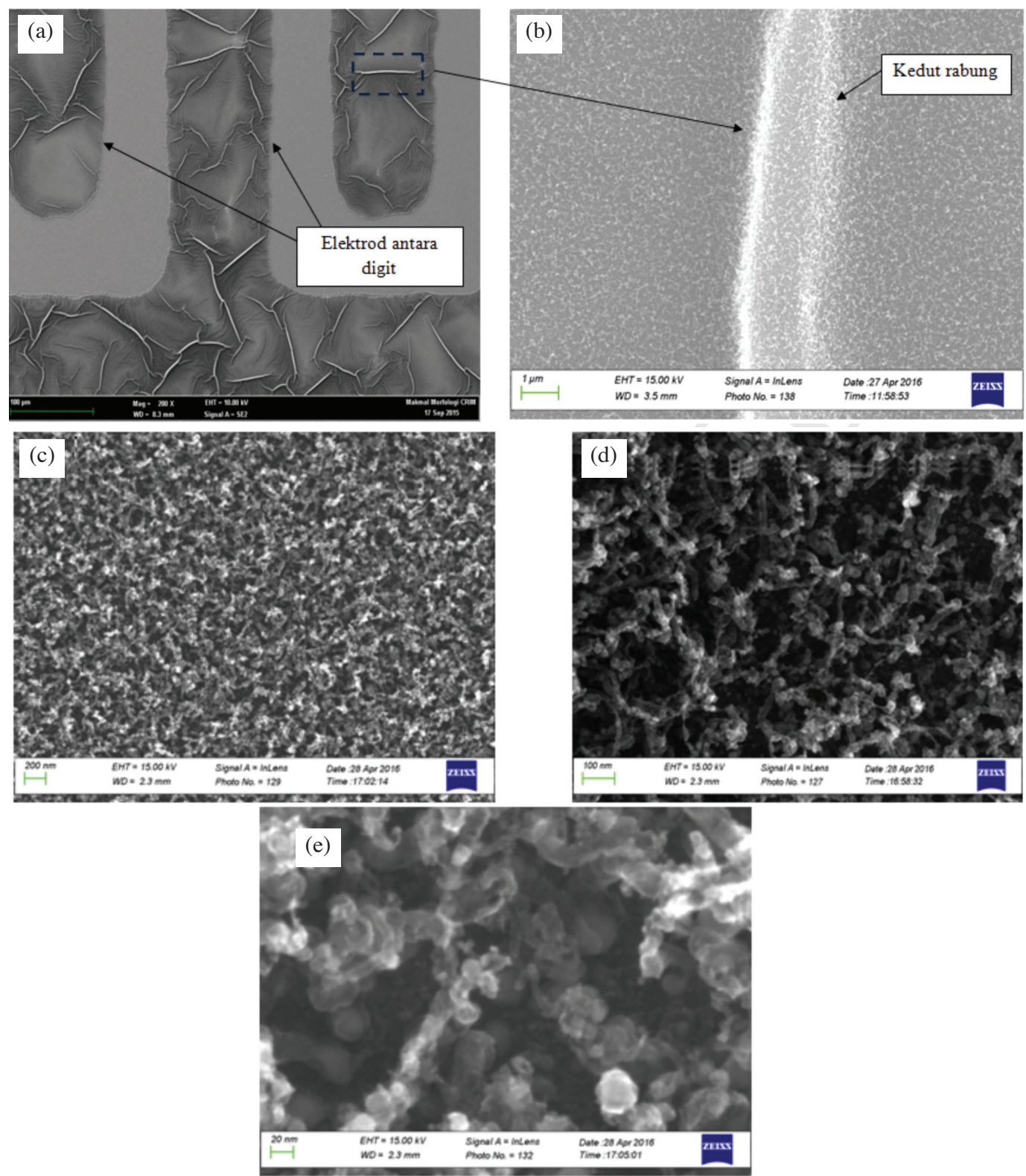

RAJAH 5. (a). Imej FESEM bagi morfologi struktur grafin pada permukaan elektrod, (b). Struktur kedutan pada permukaan elektrod, (c) $200 \mathrm{~nm}$, (d) $100 \mathrm{~nm}$, (e) $20 \mathrm{~nm}$

XPS grafin yang tumbuh pada lapisan $\mathrm{Ni}$ pada suhu $800^{\circ} \mathrm{C}$, kuasa plasma 40 Watt dan masa selama 10 min. C-C berada pada $284.5 \mathrm{eV}$, yang menunjukkan ikatan karbon $\mathrm{sp}^{2}$. Puncak ini mengesahkan kehadiran grafin pada lapisan $\mathrm{Ni}$ pada elektrod antara digit.

\section{KESIMPULAN}

Kesimpulannya, kami telah berjaya menghasilkan kualiti grafin yang baik dan beberapa lapisan grafin terbentuk iaitu sebanyak 5 lapisan pada suhu $1000^{\circ} \mathrm{C}$ berdasarkan analisis spektroskopi Raman. Daripada semua analisis yang telah dilakukan, dapat disimpulkan bahawa pengaruh suhu terhadap pertumbuhan grafin memainkan peranan yang amat penting untuk menghasilkan kualiti grafin yang baik.
Kualiti grafin yang baik dapat ditentukan daripada segi aspek kecacatan yang rendah yang boleh dilihat pada puncak D. Pada suhu $600^{\circ} \mathrm{C}$, walaupun kekasaran permukaan rendah, tetapi daripada segi aspek kecacatan menunjukkan kecacatan yang tinggi dan seterusnya menunjukkan kualiti grafin yang tidak begitu baik jika dibandingkan dengan pertumbuhan grafin pada suhu $1000^{\circ} \mathrm{C}$. Selain itu, dapat disimpulkan bahawa peningkatan suhu membawa kepada pengurangan lapisan grafin yang terhasil.

\section{PENGHARGAAN}

Penulis ingin mengucapkan terima kasih kepada Kementerian Pendidikan Malaysia (KPM) untuk bantuan dana melalui geran LRGS/2015/UKM-UKM/NANOMITE/04/01 dan FRGS/1/2014/ TK04/UKM/02/2. 
(a)

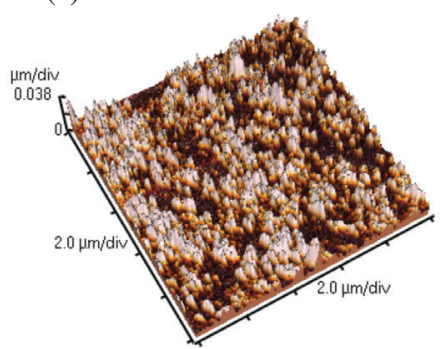

(c)

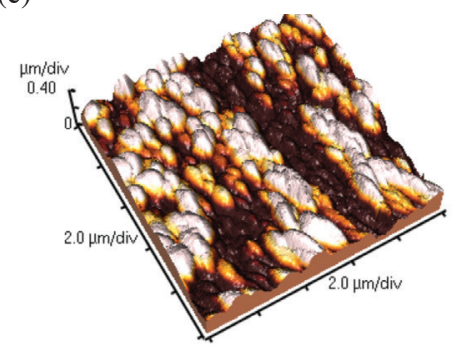

(b)



(d)

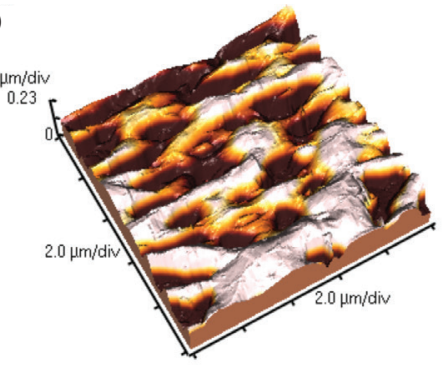

RAJAH 6. Imej AFM pada suhu pertumbuhan grafin yang berbeza (a) $400^{\circ} \mathrm{C}$ (b) $600^{\circ} \mathrm{C}$ (c) $800^{\circ} \mathrm{C}$ (d) $1000^{\circ} \mathrm{C}$

JADUAL 2. Kekasaran permukaan pada suhu yang berbeza

\begin{tabular}{cc}
\hline Suhu $\left({ }^{\circ} \mathrm{C}\right)$ & Kekasaran permukaan $($ RMS $)$ \\
\hline 400 & $8.99 \mathrm{~nm}$ \\
600 & $9.23 \mathrm{~nm}$ \\
800 & $90.46 \mathrm{~nm}$ \\
1000 & $97.25 \mathrm{~nm}$ \\
\hline
\end{tabular}

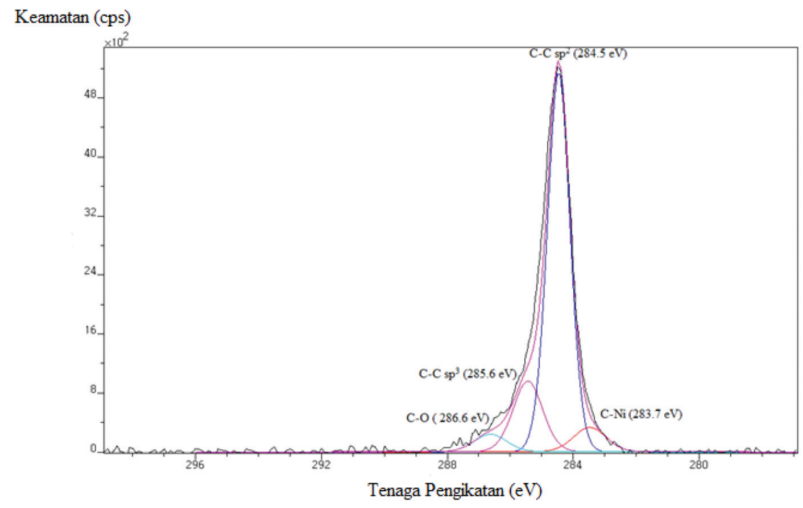

RAJAH 7. Spektrum XPS karbon atas lapisan Nikel pada suhu $800^{\circ} \mathrm{C}$

\section{RUJUKAN}

Aziz, N.A., Bais, B., Hamzah, A.A. \& Majlis, B.Y. 2008. Characterization of HNA etchant for silicon microneedles array fabrication. IEEE International Conference on Semiconductor Electronics, Proceedings, ICSE pp. 203-206.

Chen, J., Bo, Z. \& Lu, G. 2015. Vertically-Oriented Graphene: PECVD Synthesis and Applications. Switzerland: Springer International Publishing.

Hamzah, A.A., Zainal Abidin, H.E., Yeop Majlis, B., Mohd Nor, M., Ismardi, A., Sugandi, G., Tiong, T.Y., Dee, C.F. \& Yunas, J. 2013. Electrochemically deposited and etched membranes with precisely sized micropores for biological fluids microfiltration. Journal of Micromechanics and Microengineering 23(7): 74007. DOI: 10.1088/09601317/23/7/074007.

Hamzah, A.A., Majlis, Y. \& Ahmad, I. 2007. HF etching of sacrificial spin-on glass in straight and junctioned microchannels for MEMS microstructure release. $J$. Electrochem. Soc. 154(8): D376-D382.

Hamzah, A.A., Majlis, B.Y. \& Ahmad, I. 2004. Deflection analysis of epitaxially deposited polysilicon encapsulation for MEMS devices. IEEE International Conference on Semiconductor Electronics. pp. 611-614. DOI: 10.1109/ SMELEC.2004.1620960.

Ho, M.Y., Khiew, P.S., Isa, D., Tan, T.K., Chiu, W.S., Chia, C.H., Hamid, M.A.A. \& Shamsudin, R. 2014. Nano Fe3 O4 -activated carbon composites for aqueous supercapacitors. Sains Malaysiana 43(6): 885-894.

Lin, Z., Ye, X., Han, J., Chen, Q., Fan, P., Zhang, H., Xie, D., Zhu, H. \& Zhong, M. 2015. Precise control of the number of layers of graphene by picosecond laser thinning. Scientific Reports 5: 11662.

Marsi, N., Majlis, B.Y., Hamzah, A.A. \& Mohd-Yasin, F. 2015. Development of high temperature resistant of $500^{\circ} \mathrm{C}$ employing silicon carbide (3C-SiC) based MEMS pressure sensor. Microsystem Technologies 21(2): 319-330.

Marsi, N., Majlis, B.Y., Hamzah, A.A. \& Mohd-Yasin, F. 2012. Comparison of mechanical deflection and maximum stress of $3 \mathrm{C} \mathrm{SiC}$ - and si-based pressure sensor diaphragms for extreme environment. 2012 10th IEEE International Conference on Semiconductor Electronics, ICSE 2012 - Proceedings. pp. 186-190.

Moon, K., Li, Z., Yao, Y., Lin, Z., Liang, Q., Agar, J., Song, M., Liu, M. \& Wong, C.P. 2010. Graphene for ultracapacitors. Proceedings - Electronic Components and Technology Conference. pp. 1323-1328.

Novoselov, K.S., Fal'ko, V.I., Colombo, L., Gellert, P.R., Schwab, M.G. \& Kim, K. 2012. A roadmap for graphene. Nature 490(7419): 192-200 
Terasawa, T.O. \& Saiki, K. 2012. Growth of graphene on Cu by plasma enhanced chemical vapor deposition. Carbon 50(3): 869-874.

Wang, Y.Y., Ni, Z.H., Yu, T., Shen, Z.X., Wang, H.M., Wu, Y.H., Chen, W. \& Wee, A.T.S. 2008. Raman studies of monolayer graphene: The substrate effect. Journal of Physical Chemistry C 112(29): 10637-10640.

Zainal Abidin, H.E., Hamzah, A.A., Majlis, B.Y., Yunas, J., Abdul Hamid, N. \& Abidin, U. 2013. Electrical characteristics of double stacked Ppy-PVA supercapacitor for powering biomedical MEMS devices. Microelectronic Engineering 111: 374-378.

Zheng, B., Yang, Y., Chen, J., Yu, K., Yan, J. \& Cen, K. 2013. Plasma-enhanced chemical vapor deposition synthesis of vertically oriented graphene nanosheets. Nanoscale 5(12): 5180-5204.

Zheng, B., Wen, Z., Kim, H., Lu, G., Yu, K. \& Chen, J. 2012. Onestep fabrication and capacitive behavior of electrochemical double layer capacitor electrodes using vertically-oriented graphene directly grown on metal. Carbon 50(12): 43794387.
Zhu, Y., Murali, S., Cai, W., Li, X., Suk, J.W., Potts, J.R. \& Ruoff, R.S. 2010. Graphene and graphene oxide: Synthesis, properties, and applications. Advanced Materials 22(35): 3906-3924.

Institute of Microengineering and Nanoelectronics (IMEN)

Universiti Kebangsaan Malaysia

43600 UKM Bangi, Selangor Darul Ehsan

Malaysia

*Pengarang untuk surat-menyurat; email: azlanhamzah@ukm. edu.my

Diserahkan: 23 Disember 2016

Diterima: 17 Februari 2017 